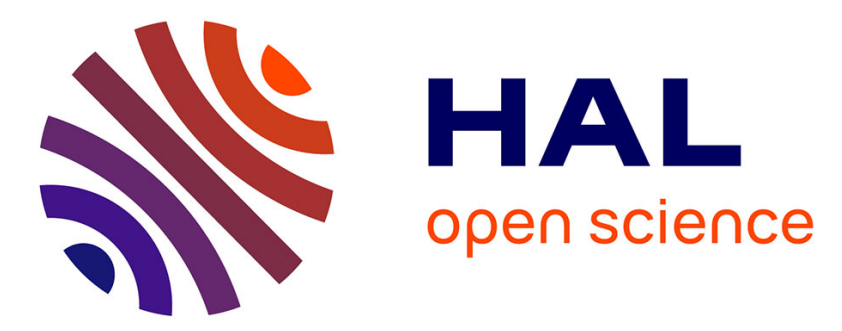

\title{
Opinion about seasonal influenza vaccination among the general population 3 years after the $\mathrm{A}(\mathrm{H} 1 \mathrm{~N} 1)$ pdm2009 influenza pandemic
}

Karine Boiron, Marianne Sarazin, Marion Debin, Jocelyn Raude, Louise

Rossignol, Caroline Guerrisi, Didi Odinkemelu, Thomas Hanslik, Vittoria

Colizza, Thierry Blanchon

\section{To cite this version:}

Karine Boiron, Marianne Sarazin, Marion Debin, Jocelyn Raude, Louise Rossignol, et al.. Opinion about seasonal influenza vaccination among the general population 3 years after the A(H1N1)pdm2009 influenza pandemic. Vaccine, 2015, 33 (48), pp.6849-6854. 10.1016/j.vaccine.2015.08.067. inserm01245493

\section{HAL Id: inserm-01245493 https://www.hal.inserm.fr/inserm-01245493}

Submitted on 17 Dec 2015

HAL is a multi-disciplinary open access archive for the deposit and dissemination of scientific research documents, whether they are published or not. The documents may come from teaching and research institutions in France or abroad, or from public or private research centers.
L'archive ouverte pluridisciplinaire HAL, est destinée au dépôt et à la diffusion de documents scientifiques de niveau recherche, publiés ou non, émanant des établissements d'enseignement et de recherche français ou étrangers, des laboratoires publics ou privés. 
Opinion aboutseasonal influenza vaccinationamong the general population 3 years after the A(H1N1)pdm2009 influenzapandemic

Karine Boiron ${ }^{1,2}$, Marianne Sarazin ${ }^{2,3}$, Marion Debin ${ }^{1,2}$, Jocelyn Raude $^{4}$, Louise Rossignol ${ }^{1,}$

${ }^{2}$, Caroline Guerrisi ${ }^{1,2}$,Didi Odinkemelu ${ }^{1,2}$, Thomas Hanslik ${ }^{2,5,6}$, Vittoria Colizza ${ }^{1,2}$, Thierry Blanchon $^{1,2}$

1. Sorbonne Universités, UPMC Univ Paris 06, UMR_S 1136, F-75012, Paris, France.

2. INSERM, UMR_S 1136, F-75012, Paris, France.

3. Département d'information médicale, Centre Hospitalier, Firminy, France

4. Department of Social and Behavioral Sciences, EHESP Rennes, Sorbonne Paris Cité, France.

5. APHP, Service de médecine interne, hôpital Ambroise-Paré, 92100 Boulogne-Billancourt, France,

6. UFR des sciences de la santé Simone-Veil, Université de Versailles - Saint-Quentin-en-Yvelines, 78280 Versailles, France

\section{Keywords}

Influenza, Vaccination, Epidemiological factors, Population surveillance

\section{Highlights}

- In France, 39\% reported a positive opinion regarding seasonal flu vaccination

- $39 \%$ and $22 \%$ reported a neutral and a negative opinion

- Healthy young adults were more inclined to have neutral or negative opinions

-As well as those preferring homeopathic treatments

- And those who did not work in contact with elderly or sick individuals 


\section{Contact information}

Correspondingauthors : Thierry Blanchon, Réseau Sentinelles, INSERM UPMC - UMR S 1136,

Université Pierre et Marie Curie, site Saint-Antoine, 27 rue Chaligny, 75012 Paris, France

Tel. : 33144738435 - Fax : 33144738454

Email: thierry.blanchon@upmc.fr 


\begin{abstract}
Objective:Toassess theopinions of the French general population aboutseasonal influenza vaccinationthree years after the $\mathrm{A}(\mathrm{H} 1 \mathrm{~N} 1) \mathrm{pdm} 09$ pandemic and identify factors associated with a neutral or negative opinion aboutthis vaccination.

Study design:The study was conducted using data collected from 5374 participants during the 2012/2013 season of the GrippeNet.fr study. The opinion about seasonal influenza vaccination was studied on three levels ("positive", "negative" or "neutral"). The link between the participant's characteristics and their opinion regarding the seasonal influenza vaccination were studied using a multinomial logistic regression with categorical variables. The "positive" opinion was used as the reference for identifying individuals being at risk of having a "neutral" or a "negative" opinion.

Results:Among the participants, 39\% reported having a positive opinion about seasonal influenza vaccine, $39 \%$ a neutral opinion, and $22 \%$ a negative opinion. Factors associated with a neutral or negative opinion were young age, low educational level, lack of contact with sick or elderly individuals, lack of treatment for a chronic disease and taking a homeopathic preventive treatment. Conclusions: These results show that an important part of the French population does not have a positive opinion about influenza vaccination in France.Furthermore, it allows outlining the profiles of particularly reluctant individuals who could be targeted by informative campaigns.
\end{abstract}




\section{Introduction}

According to the World Health Organization(WHO), seasonal influenza is a major cause of morbidity and mortality worldwide, and is responsible for 3 to 5 million serious illnesses and for 250,000 to 500,000 deaths each year, depending on virulence and epidemic duration (1). In France, influenza is the reason for 700,000 to 4.8 million influenza-like-illnesses (ILI) consultations each year, which represents 1 to $8 \%$ of the general population $(2,3)$, and $0.3( \pm 0.6)$ to 4 ( \pm 2.8$)$ work days lost per person and per influenza episode (4). Mortality is difficult to estimate because it includes influenza related deaths, but also deaths recorded for other reasons such as "pneumonia" or "cardiovascular diseases"(5). Thus, it is estimated from 0 to 24 deaths per 100,000 inhabitants and per flu epidemic from 1972 to 2010 (6), whereindividualsaged over 65 accounted for $90 \%$ of deaths $(7,8)$.

Vaccination isthe main preventive measure advocated by the WHOagainst influenza. In France vaccination is recommended for individuals at risk of developing complicated forms of diseases likeindividuals over age 65, pregnant women, obese individuals, healthcare workers, and individuals living with a chronic disease for 6 months or more (9). Vaccination of these groups remains a major public health concern withthe objective to reachan immunization coverage of $75 \%$ in $2015(10)$.

The vaccination campaign management during the 2009 influenza pandemic $A(H 1 N 1)$ appears to have strongly affected the acceptability of vaccination among the French population, particularly vaccination against seasonal influenza. During the pandemic, several studies wereconductedin France to assessperceptions of the $\mathrm{A}(\mathrm{H} 1 \mathrm{~N} 1) \mathrm{pdm} 09$ vaccine in the general population(11), as well as among health professionals (12-15). The main results revealedexistingdoubts aboutthe severity of the pandemic, the safety and efficacy of thevaccine adjuvant, and the role of the physician in 
patients' adherence to the vaccination. Similar results were also obtained in other countries(1622).

The campaign of 2009 resulted in France with only $7.9 \%$ of the general population being vaccinated, contrary to expectations for a larger coverage (23). A study published in 2012 showeda decrease in influenza vaccination coverage among "at risk" populations between 2009 and the two subsequent seasons 2010 and 2011 (59.8\%, 50.4\% and 51.0\% of vaccination coverage rates respectively)(24). This decrease was validated by the National Security Agency of Medicines and Health Products (ANSM), which indicated a decrease of $19.7 \%$ in the seasonal flu vaccines distribution between 2009 and 2010 (24).

In view of the aforementioned data,the objectivesof this study were to assess theseasonal influenza vaccine acceptability among the general population and factors associated with this acceptability, three years after the 2009 pandemic.

\section{Materials and methods}

The study was conducted using data collected inthe cohort GrippeNet.fr, a web-based participative study conducted in France(25).Developed by the French National Institute of Health and Medical Research (Inserm), Pierre and Marie Curie University (UPMC) and the French Institute for Public Health Surveillance (InVS), this project is part of a broader European study,Influenzanet (http://www.influenzanet.eu)(26), whichallows monitoring ILI evolution directly in the general population. The inclusion criteria to participate in the GrippeNet.fr study include: 1) residency in France 2) comprehension of the French language 3) access to the Internet. Upon registration, participants were asked to complete a baseline questionnaire covering demographic factors (age, gender), geographicalfactors (location of home and work/school expressed at themunicipality level), socio-economic factors (household size and composition, occupation, educational level, number of daily contacts with groups of patients, children or elderly, daily transportation means), 
and health-related factors (height and weight, diet, vaccination status, pregnancy status, smoking habits,major risk conditions, and opinion about seasonal influenza vaccination evaluated over three levels ("positive", "negative" or "neutral").Subsequently, they were invited to describe weekly clinical symptoms during the flu season. From November 2012 to April 2013, 6059 individualsin France voluntarily contributed to the data collection for GrippeNet.frThe representativeness of the participants was recently published elsewhere (25).The GrippeNet.fr population was not representative of the general population in terms of age and gender, however all ageclasses were represented, including the older classes (65+ years old), generally less familiar with the digital world, butconsidered at higher risk for influenza complications. Once adjusted on demographic indicators, the GrippeNet.fr populationwas found to be more frequently employed, with a higher education level and vaccination rate with respect to the generalpopulation. A similar propensity to commute for work to different regions was observed, and no significant difference wasfound for asthma and diabetes.

\section{Study population}

From the GrippeNet.fr participant pool, those above 18 years who completed the baseline questionnaire for the 2012/2013 season (November 2012-April 2013) were included in the study. This amounts to 5374 of the 6059 GrippeNet.fr participants; 659 children, 19 persons who didn't specify their ages,and 7 persons living outside Francewere excluded from the study.

\section{Data analysis}

A description of the population included in the study was conducted and outlierswereverified, corrected or excluded as needed.The opinion about seasonal influenza vaccinationwas studied usingthe three levels proposed in the baseline questionnaire ("positive", "negative" or "neutral").The link between the participant'scharacteristics and their opinion regarding the seasonal influenza vaccination was studied using a multinomial logistic regressionwith categorical 
variables. The "positive"opinionserved asthe reference foridentifyingindividualsbeing at risk of having a "neutral" or a "negative" opinion. Explanatory variables included socio-demographic characteristics (age, sex, educational level, main activity, presence of children in the household), contacts during a typical day (children, old individuals, sick individuals); geographical characteristics (place of residence)and clinical characteristics. According to the national French recommendations (9), anew variable named "At risk group for influenza" was created, defined by individuals with at least one of the following characteristics: age $\geq 65$ years, body mass index $(\mathrm{BMI}) \geq 40$, pregnancy or having received aninfluenza vaccination voucher from the French government, which include patients with a chronic underlying disease. The effect of each explanatory variable was studied using univariateanalysesfirst, then multivariate analyses. Allvariables that had a p-value less than 0.2 in univariate analyses were included in the multivariate analyses. In multivariate analysis, two variables were deliberately excluded: the vaccination status variableand the variable dealing with individuals being at risk of having complicated influenza,as they were too correlatedwith the other variables of interest. Each odds ratiowas obtained from a step down multinomial logistic regression with categorical variables, using a 95\% confidence interval. All statistical analyses were performed using the R software.

\section{Results}

\section{Population's characteristics}

The study population consisted of 2018 men (38\%) and 3356 women (62\%), with amean age of50 years (Table 1). For the educational level,1569 participants (37\%) had at least a Masters degree and664 participants (16\%) had an educational level below theBachelorsdegree. Regarding employment, 2300 participants (43\%) were employedfull-timeand 1417 (26\%) were retired. All regions were represented.Most participants were living in medium size urban cities: 1373 persons (25.5\%) lived in cities with 2,000 to 10,000 habitants and $1833(34 \%)$ in cities with10,000 to 
100,000 inhabitants. Vaccination coverage against seasonal influenza was estimated to be $28 \%$ $(\mathrm{n}=1515)$ in the study population. Among the participants, $1636(31 \%)$ had at least one risk factor for complicated influenza and among them, 897 (55\%) were vaccinated against influenza.

\section{Opinion regarding influenza seasonal vaccinationand associated factors}

In our study, 2037 participants (39\%) had a positive opinion regardinginfluenza seasonalvaccination, 2052 participants (39\%) had a neutral one and 1167 participants (22\%) a negative one. Among individuals $\geq 65$ years old, 554 (55\%) had a positive opinion regarding influenza seasonal vaccination, $273(27 \%)$ had a neutral one and $179(18 \%)$ a negative one.

In multivariate analysis (Tables 2a-2b), factors significantly associated with neutral opinion comparedto a positive opinion about influenza seasonal vaccinationwere: having 35-50 yearsold comparedto 18-35 years old(OR, 0.72; 95\% CI,0.57-0.91), having at least 65 years old comparedto 18-35 years old(OR, 0.28; 0.18-0.43), taking a treatment for chronic diseases (OR, 0.48; 0.37-0.62), taking preventive homeopathic treatment during the winter season (OR, 3.29; 2.70-4.00), the frequency of colds orILI, contact with elderly (OR, 0.70; 0.52-0.94) or contact with patients (OR, 0.57; 0.45-0.72), at least one child from 5 to18 years in the household(OR, 0.76; 0.62-0.95), being a student rather than an employee (OR, 1.54; 1.04-2.28), having a low study level, living in medium-size cities (OR, 0.68; 0.54-0.86) and living in some regions.

Factors significantly associated with a negative opinion rather than a positive one about seasonal flu vaccines(Tables 2a-2b) were:having 50-65 yearsold compared to 18-35 years old(OR, 0.56; 0.41-0.77), having at least 65 years old compared to $18-35$ years old(OR, 0.38; 0.23-0.61), obesity $(\mathrm{BMI} \geq 40)(\mathrm{OR}, 2.23 ; 1.02-4.87)$, taking treatment for a chronic disease $(\mathrm{OR}, 0.54 ; 0.40-0.72)$, taking preventive homeopathic treatment during the winter season (OR, 4.85; 3.84-6.14), the frequency of ILI or colds, daily contact with patients (OR, 0.54; 0.40-0.73), at least one 5-18 
years old child in the household"(OR, 1.26; 1.03-1.53), having a low study level and living in certain regions.

\section{Discussion}

This work provides an overview of the opinions about influenza seasonal vaccination in the general population using data from GrippeNet.fr study, as well as factors related to a negative or neutral opinion of thisvaccination.

In the study, almost a quarter of participants reported a negative opinion of influenza seasonal vaccination and 39\% a neutral one. To our knowledge, few studies haveaddressed the question of opinions onvaccination against the seasonal flu. Most studies addressvaccination acceptability based onimmunization coverage rates of: healthcare workers $(12,27,28)$, individualstargeted by the recommendations (29-31) or the general population $(28,32,33)$. In France the Health Barometer has studied the acceptability of influenza vaccinations from a similar perspective. A recent study(34)focused on changes in attitude of 18 to 75 years old Frenchindividualsregarding vaccination by comparing Health Barometer studiescarried outin 2000, 2005 and 2010 (data collected between October 2009 to June 2010 for the last one). This study showed a strong increase in adverse opinions against vaccination in general: 8.5\% in 2000, 9.6\% in 2005 and $38.2 \%$ in 2010. In 2010, 47\% reported a negative opinion for at least one type of influenzavaccination (based on 3 possible and non-exclusive answers: $42.1 \%$ for the vaccination against the $\mathrm{A}(\mathrm{H} 1 \mathrm{~N} 1)$ pdm09pandemic influenza, 7.7\% for the influenza seasonal vaccination, and $5.7 \%$ for influenzavaccination in general) (unpublished Inpes data). Although there has been no Health Barometer since 2010,the gradual decrease of the vaccination coverage rate against influenza among individualsat risk of complications(24) suggests that vaccine reluctancehas increased in recent years. Vaccination coverage rateagainst seasonal flu among at risk individuals was $50.1 \%$ in $2012-2013$ (respectively $51.8 \%$ and $51.7 \%$ in 2010/2011 and 2011/2012) which 
reveals a gradual decrease since 2009/2010 (60.2\%) (35). This decrease in the flu vaccination coverage rates is also observed in Spain (27), Switzerland (36), Germany (37), whereasthe situation is more nuanced in the UK (38). In the United States an isolated decrease of the vaccination coverage rate was observed among adults in 2011/2012 (39).

In this study, we highlighted factors associated with opinion on flu vaccination for the general population and not only on at risk individuals currently targeted by recommendations. It allowsoutlining theprofiles linked with neutral or negative opinion regardingflu vaccination. Individualsmore inclined to have neutral or negative opinions were healthy young adults, those preferring homeopathy and those who did not work in contact with elderly or sickindividuals. This profile appeared similar to those of parents of children from 6 to 59 months of age targeted by the most recent WHO flu vaccine recommendations (40), independently of the fact that children may be at risk of complication. This suggeststhat it may be difficult to implement such a measure in France. In Europe, only Finland has implemented a vaccination program for young children, the UK planned to do the samefor children ages2-17 years old (41). Other countries, like the United States, recommend the vaccination of the entire population from 6 months of age (42). Even if the immunization schedule was simplified in 2013 in France(9),it stillprovides a large number of vaccinations in young children. The addition of a new yearly vaccine against influenza in this age groupseems to be particularly difficult.

Individuals with a severe obesityhad a more frequently negative opinion of the influenza vaccine, even though they have been targeted by the vaccine recommendations since 2010 (Notice HCSP 29/12/2010). This resistance towards theinfluenza vaccination is confirmed by a lowvaccination coverage ratein this group (around 25\%)(43). It is difficult for the NationalHealth Insurance to obtain theBMI of patients in orderto send them a vaccination voucher and appropriate information. Health professionals and the media are, as a result, responsible for vaccinationpromotion. 
However, when looking at the posters and leaflets of the last immunization campaigns(44-46), we observed that the focus was primarily on the elderly and patients with chronic diseases. Obese individuals are mentioned in several documents, but are not directly targeted by these campaigns. The results of the study also suggestthat information on the influenza vaccine should be targeted more widelynot restricting it only to individuals at risk, but also considering social characteristics for example,students, as already successfully tested in the USA(47), or individuals with a low education level, who are more likely tohavea negative opinion of theflu vaccine.

Even if our assumptions are consistent with the literature, this study has some limitations.First of all, our population is not fully representative of the French population (25). A web-based participative study may have inhibited the participation of certain individuals(such asthe elderly orindividuals of low social status); there is also a risk of over-representation of individualssensitive to health issues or adverse to vaccination. The Internet is however becoming more important and pervasive in our daily lives, regardless of age; hence itoffers the opportunity to reach an increasinglylarger number of individuals. Taking into account opinions on vaccinationas the main criterion for the decision and not theact of vaccinationitself allowed us to study the general population and not only targeted individuals. Renewal of studies using this same criterion would allow a better assessment of how the opinion evolvesamong different groups of thegeneral population in France, and provide the information needed for a more efficient and prompt reaction before such evolutionhas an impact on thevaccination coverage rate.

Finally,opinions regarding vaccinationagainstseasonal influenzahave changedin the general populationsince the $\mathrm{A}(\mathrm{H} 1 \mathrm{~N} 1) \mathrm{pdm} 2009$ pandemicinfluenza witha significant increase inthe number of individuals with a negative opinion andagradual decline invaccination coverage rateamong at riskindividuals. Further studies areneeded to better understandthepsychosocialmechanisms underlyingthis change ofopinionwith the aim of conductingtargeted and adaptivecommunication 
campaigns. Apart fromthe decline inprotectionof individualsat riskofcomplicatedinfluenza duringseasonal epidemics, the major risk is a rejection of vaccination by the general population inthe event of another influenza pandemic, with importanthealth and social consequences.

\section{Funding}

This study was supported by the French National Institute of Health and Medical Research (Inserm) and the University Pierre and Marie Curie (UPMC). The funding was not specific for the study described in this article. The funder had no role in study design, data collection, data analysis, data interpretation, writing of the report, or in the decision to submit this article for publication. All researchers' decisions have been entirely independent from funders.

\section{Conflict of interest statement}

Authors have nothing to disclose. 


\section{REFERENCES}

1. World Health Organization. Seasonal influenza. 2009 [cited April 2013]; Available from: http://www.who.int/mediacentre/factsheets/fs211/en/index.html.

2. Viboud C, Pakdaman K, Boelle PY, Wilson ML, Myers MF, Valleron AJ, Flahault A. Association of influenza epidemics with global climate variability. Eur J Epidemiol. 2004;19(11):1055-9.

3. Turbelin C, Souty C, Pelat C, Hanslik T, Sarazin M, Blanchon T, Falchi A. Age distribution of influenza like illness cases during post-pandemic $\mathrm{A}(\mathrm{H} 3 \mathrm{~N} 2)$ : comparison with the twelve previous seasons, in France. PLoS One. 2013;8(6):e65919.

4. Carrat F, Sahler C, Rogez S, Leruez-Ville M, Freymuth F, Le Gales C, Bungener M, Housset B, Nicolas M, Rouzioux C. Influenza burden of illness: estimates from a national prospective survey of household contacts in France. Arch Intern Med. 2002;162(16):1842-8.

5. Thompson WW, Weintraub E, Dhankhar P, Cheng PY, Brammer L, Meltzer MI, Bresee JS, Shay DK. Estimates of US influenza-associated deaths made using four different methods. Influenza Other Respi Viruses. 2009;3(1):37-49.

6. Lemaitre M, Carrat F, Rey G, Miller M, Simonsen L, Viboud C. Mortality burden of the 2009 A/H1N1 influenza pandemic in France: comparison to seasonal influenza and the A/H3N2 pandemic. PLoS One. 2012;7(9):e45051.

7. Carrat F, Valleron AJ. Influenza mortality among the elderly in France, 1980-90: how many deaths may have been avoided through vaccination? J Epidemiol Community Health. 1995;49(4):419-25.

8. Centers for Disease Control and Prevention. Estimates of deaths associated with seasonal influenza United States, 1976-2007. MMWR Morb Mortal Wkly Rep. 2010;59(33):1057-62.

9. Haut Conseil de la Santé Publique. Vaccination schedule and recommendations in France. BEH. 2013;14-15:129-60.

10. Commission of the european communities. Council recommendation on seasonal influenza vaccination. Brussels: The institute; 2009.

11. Schwarzinger M, Flicoteaux R, Cortarenoda S, Obadia Y, Moatti JP. Low acceptability of A/H1N1 pandemic vaccination in French adult population: did public health policy fuel public dissonance? PLoS One. 2010;5(4):e10199.

12. Tanguy M, Boyeau C, Pean S, Marijon E, Delhumeau A, Fanello S. Acceptance of seasonal and pandemic a (H1N1) 2009 influenza vaccination by healthcare workers in a french teaching hospital. Vaccine. 2011;29(25):4190-4.

13. Blank PR, Bonnelye G, Ducastel A, Szucs TD. Attitudes of the general public and general practitioners in five countries towards pandemic and seasonal influenza vaccines during season 2009/2010. PLoS One. 2012;7(10):e45450.

14. Schwarzinger M, Verger P, Guerville MA, Aubry C, Rolland S, Obadia Y, Moatti JP. Positive attitudes of French general practitioners towards A/H1N1 influenza-pandemic vaccination: a missed opportunity to increase vaccination uptakes in the general public? Vaccine. 2010;28(15):2743-8.

15. Valour F, Benet T, Chidiac C. Pandemic A(H1N1)2009 influenza vaccination in Lyon University Hospitals, France: perception and attitudes of hospital workers. Vaccine. 2013;31(4):592-5.

16. Ferrante G, Baldissera S, Moghadam PF, Carrozzi G, Trinito MO, Salmaso S. Surveillance of perceptions, knowledge, attitudes and behaviors of the Italian adult population (18-69 years) during the 2009-2010 A/H1N1 influenza pandemic. Eur J Epidemiol. 2011;26(3):211-9. 
17. Lin Y, Huang L, Nie S, Liu Z, Yu H, Yan W, Xu Y. Knowledge, attitudes and practices (KAP) related to the pandemic (H1N1) 2009 among Chinese general population: a telephone survey. BMC Infect Dis. 2011;11:128.

18. Eastwood K, Durrheim DN, Jones A, Butler M. Acceptance of pandemic (H1N1) 2009 influenza vaccination by the Australian public. Med J Aust. 2010;192(1):33-6.

19. Lau JT, Yeung NC, Choi KC, Cheng MY, Tsui HY, Griffiths S. Acceptability of A/H1N1 vaccination during pandemic phase of influenza A/H1N1 in Hong Kong: population based cross sectional survey. BMJ. 2009;339:b4164.

20. Virseda S, Restrepo MA, Arranz E, Magan-Tapia P, Fernandez-Ruiz M, de la Camara AG, Aguado JM, Lopez-Medrano F. Seasonal and Pandemic A (H1N1) 2009 influenza vaccination coverage and attitudes among health-care workers in a Spanish University Hospital. Vaccine. 2010;28(30):4751-7.

21. Seale H, Heywood AE, McLaws ML, Ward KF, Lowbridge CP, Van D, MacIntyre CR. Why do I need it? I am not at risk! Public perceptions towards the pandemic (H1N1) 2009 vaccine. BMC Infect Dis. 2010;10:99.

22. Prematunge C, Corace K, McCarthy A, Nair RC, Pugsley R, Garber G. Factors influencing pandemic influenza vaccination of healthcare workers-A systematic review. Vaccine. 2012.

23. Guthmann JP BA, Nicolau J, Lévy-Bruhl D. Insufficient influenza A(H1N1)09 vaccination coverage in the global population and high risk groups during the 2009-2010 pandemic in France. BEHweb. 2010;n³.

24. Tuppin P, Choukroun S, Samson S, Weill A, Ricordeau P, Allemand H. [Vaccination against seasonal influenza in France in 2010 and 2011: decrease of coverage rates and associated factors]. Presse Med. 2012;41(11):e568-76.

25. Debin M, Turbelin C, Blanchon T, Bonmarin I, Falchi A, Hanslik T, Levy-Bruhl D, Poletto C, Colizza V. Evaluating the feasibility and participants' representativeness of an online nationwide surveillance system for influenza in france. PLoS One. 2013;8(9):e73675.

26. Marquet RL, Bartelds AI, van Noort SP, Koppeschaar CE, Paget J, Schellevis FG, van der Zee J. Internet-based monitoring of influenza-like illness (ILI) in the general population of the Netherlands during the 2003-2004 influenza season. BMC Public Health. 2006;6:242.

27. Sanchez-Paya J, Hernandez-Garcia I, Garcia-Roman V, Camargo-Angeles R, Barrenengoa-Sanudo J, Villanueva-Ruiz CO, Martinez HR, Gonzalez-Hernandez M. Influenza vaccination among healthcare personnel after pandemic influenza H1N1. Vaccine. 2012;30(5):911-5.

28. Liu S, Yuan H, Liu Y, Du J, Zhang X, Wang J, Che X, Xu E. Attitudes of seasonal influenza vaccination among healthcare worker and general community population after pandemic influenza A/H1N1 in Hangzhou. Hum Vaccin. 2011;7(10):1072-6.

29. Tuppin P, Samson S, Weill A, Ricordeau P, Allemand H. Seasonal influenza vaccination coverage in France during two influenza seasons (2007 and 2008) and during a context of pandemic influenza A(H1N1) in 2009. Vaccine. 2011;29(28):4632-7.

30. Ahluwalia IB, Singleton JA, Jamieson DJ, Rasmussen SA, Harrison L. Seasonal influenza vaccine coverage among pregnant women: pregnancy risk assessment monitoring system. J Womens Health (Larchmt). 2011;20(5):649-51.

31. Szucs T, Muller D. Influenza vaccination coverage rates in five European countries-a populationbased cross-sectional analysis of two consecutive influenza seasons. Vaccine. 2005;23(43):5055-63.

32. Vaux S, Van Cauteren D, Guthmann JP, Le Strat Y, Vaillant V, de Valk H, Levy-Bruhl D. Influenza vaccination coverage against seasonal and pandemic influenza and their determinants in France: a cross-sectional survey. BMC Public Health. 2011;11:30. 
33. Lu PJ, Santibanez TA, Williams WW, Zhang J, Ding H, Bryan L, O'Halloran A, Greby SM, Bridges CB, Graitcer SB, Kennedy ED, Lindley MC, Ahluwalia IB, Lavail K, Pabst LJ, Harris L, Vogt T, Town M, Singleton JA. Surveillance of influenza vaccination coverage - United States, 2007-08 through 2011-12 influenza seasons. MMWR Surveill Summ. 2013;62 Suppl 4:1-29.

34. Peretti-Watel P, Verger P, Raude J, Constant A, Gautier A, Jestin C, Beck F. Dramatic change in public attitudes towards vaccination during the 2009 influenza A(H1N1) pandemic in France. Euro Surveill. 2013;18(44).

35. InVS. Influenza vaccination coverage between 2008 and 2013. [cited November 2013]; Available from: http://www.invs.sante.fr/Dossiers-thematiques/Maladies-infectieuses/Maladies-a-preventionvaccinale/Couverture-vaccinale/Donnees/Grippe.

36. Schindler M, Blanchard-Rohner G, Meier S, Martinez de Tejada B, Siegrist CA, Burton-Jeangros C. Vaccination against seasonal flu in Switzerland: The indecision of pregnant women encouraged by healthcare professionals. Rev Epidemiol Sante Publique. 2012;60(6):447-53.

37. Bohmer MM, Walter D, Falkenhorst G, Muters S, Krause G, Wichmann O. Barriers to pandemic influenza vaccination and uptake of seasonal influenza vaccine in the post-pandemic season in Germany. BMC Public Health. 2012;12:938.

38. Departement of Health (England). Immunisation against infectious disease : the Green Book, 2013. Available

from: https://www.gov.uk/government/uploads/system/uploads/attachment_data/file/239268/Green_Book_C hapter 19 v5 2 final.pdf.

39. Center for Disease Control and Prevention. Flu Vaccination Coverage in United States 2013 [cited November 2013]; Available from: http://www.cdc.gov/flu/fluvaxview/coverage-1213estimates.htm.

40. World Health Organization. Vaccines against influenza WHO position paper - November 2012. Wkly Epidemiol Rec. 2012;87(47):461-76.

41. Heikkinen T, Tsolia M, Finn A. Vaccination of healthy children against seasonal influenza: a European perspective. Pediatr Infect Dis J. 2013;32(8):881-8.

42. Center for Disease Control and Prevention. Prevention and control of seasonal influenza with vaccines. Recommendations of the Advisory Committee on Immunization Practices-United States, 2013-2014. MMWR Recomm Rep. 2013;62(RR-07):1-43.

43. Privileggio L, Falchi A, Grisoni ML, Souty C, Turbelin C, Fonteneau L, Hanslik T, Kerneis S. Rates of immunization against pandemic and seasonal influenza in persons at high risk of severe influenza illness: a cross-sectional study among patients of the French Sentinelles general practitioners. BMC Public Health. 2013;13:246.

44. Cnam. [2011/2012 seasonal influenza vaccination campaign]. [cited November 2013]; Available from: $\quad$ http://www.sante.gouv.fr/IMG/pdf/Vaccination_contre_la_grippe_saisonniere_Lancement de la campagne 2011-2012.pdf.

45. Cnam. [2010/2011 seasonal influenza vaccination campaign]. [cited November 2013]; Available from: $\quad$ http://www.ameli.fr/espace-presse/communiques-et-dossiers-de-presse/les-dernierscommuniques-de-la-caisse-nationale/detail-d-un-communique/1357.php.

46. Cnam. [2013/2014 seasonal influenza vaccination campaign : a public health priority]. [cited November 2013]; Available from: http://www.sante.gouv.fr/campagne-de-vaccination-contre-lagrippe-saisonniere-2013.html.

47. Shropshire AM, Brent-Hotchkiss R, Andrews UK. Mass media campaign impacts influenza vaccine obtainment of university students. J Am Coll Health. 2013;61(8):435-43. 
Table 1: Participants characteristics $(\mathrm{N}=5374)$

\section{Characteristics}

Age, mean [quartile]

Male, n (\%)

Level of education, $\mathrm{n}(\%)$

Lower than High School certificate

High School certificate or equivalent

Bachelor degree

Master degree or higher

Main activity, n (\%)

Full-time employment

Part-time employment

Self-employed

Student

Home-maker (e.g. housewife)

Unemployed

Long-term sick-leave or Parental leave

Retired

Place of residence, $\mathrm{n}(\%)$

Rural

Urban - Isolated Town

Urban - Suburbs

Urban - City

Population of the municipality, n (\%)

$<200$

$[200-2,000)$

$[2000-10,000)$

$[10,000-100,000)$

$[100,000-1.000,000)$

$\geq 1.000,000$

At- risk group for influenza, $\mathrm{n}(\%) *$

Asthma, n (\%) **

Other Chronic diseases, n (\%) ***

Receiving seasonal flu vaccine (season 2012/2013), n (\%)

Influenza preventive homeopathic treatment, $\mathrm{n}(\%)$

\section{Results}

$50.5[38 ; 62.5]$

$2018(38)$

$664(16)$

$764(18)$

1239 (29)

1569 (37)

2300 (43)

525 (10)

298 (5.5)

297 (5.5)

207 (4)

$184(3)$

93 (2)

1417 (26)

1032 (19)

401 (7.5)

2036 (38)

1905 (35.5)

$93(1.5)$

1009 (19)

$1373(25.5)$

1833 (34)

745 (14)

321 (6)

1636 (31)

330 (6)

736 (14)

$1515(28)$

1133 (21)

* At least one criteria between Age $\geq 65$ years, BMI $\geq 40$, pregnancy, voucher reception for influenza vaccination

** Regular medication for asthma

*** Regular medication for chronic diseases like diabetes, chronic lung disorder (besides asthma), heart disorder, kidney disorder, acquired immune deficiency 
Table 2a:Factors associated with the influenza vaccination opinion (multivaried analysis)

\begin{tabular}{|c|c|c|c|c|c|c|c|c|}
\hline Variables & $\mathbf{N}$ & $\begin{array}{c}\text { Positive } \\
\text { Opinion } \\
\text { n }(\%)\end{array}$ & $\begin{array}{c}\text { Neutral } \\
\text { Opinion } \\
\text { n }(\%)\end{array}$ & $\begin{array}{c}\text { Neutral } \\
\text { OpinionvsPositive } \\
\text { Opinion } \\
\text { OR (IC 95\%) } \\
\end{array}$ & $p$ value & $\begin{array}{c}\text { Negative } \\
\text { Opinion } \\
\text { n }(\%)\end{array}$ & $\begin{array}{l}\text { Negative Opinion vs } \\
\text { Positive Opinion } \\
\text { OR (IC 95\%) }\end{array}$ & $p$ value \\
\hline \multicolumn{9}{|l|}{ Age } \\
\hline 18 to 35 years & 995 & $269(27)$ & $498(50)$ & 1 (reference) & & $228(23)$ & 1 (reference) & \\
\hline 35 to 49 years & 1582 & $540(34)$ & $662(42)$ & $0.72(0.57 ; 0.91)$ & 0.007 & $380(24)$ & $0.85(0.65 ; 1.12)$ & 0.28 \\
\hline 50 to 64 years & 1673 & $674(40)$ & $619(37)$ & $0.48(0.36 ; 0.63)$ & $<0.001$ & $380(23)$ & $0.56(0.41 ; 0.77)$ & $<0.001$ \\
\hline$\geq 65$ years & 1006 & $554(55)$ & $273(27)$ & $0.28(0.18 ; 0.43)$ & $<0.001$ & $179(18)$ & $0.38(0.23 ; 0.61)$ & $<0.001$ \\
\hline \multicolumn{9}{|l|}{ BMI categories } \\
\hline [18 to 25) & 3127 & $1160(37)$ & $1264(40.5)$ & 1 (reference) & & $703(22.5)$ & 1 (reference) & \\
\hline$<18$ & 122 & $39(32)$ & $55(45)$ & $1.08(0.65 ; 1.80)$ & 0.76 & $28(23)$ & $0.87(0.47 ; 1.60)$ & 0.65 \\
\hline [25 to 30$)$ & 1381 & $601(43.5)$ & $506(36.5)$ & $0.96(0.81 ; 1.15)$ & 0.64 & $274(20)$ & $0.88(0.71 ; 1.09)$ & 0.24 \\
\hline [30 to 40) & 492 & $197(40)$ & $179(36.5)$ & $1.13(0.86 ; 1.48)$ & 0.39 & $116(23.5)$ & $1.15(0.84 ; 1.57)$ & 0.39 \\
\hline$\geq 40$ & 53 & $18(34)$ & $15(28)$ & $1.16(0.51 ; 2.65)$ & 0.72 & $20(38)$ & $2.23(1.02 ; 4.87)$ & 0.05 \\
\hline \multicolumn{9}{|l|}{ Regular medication for asthma } \\
\hline No & 4933 & $1882(38)$ & $1942(39.5)$ & 1 (reference) & & $1109(22.5)$ & 1 (reference) & \\
\hline Yes & 323 & $155(48)$ & $110(34)$ & $0.68(0.50 ; 0.94)$ & 0.01 & $58(18)$ & $0.62(0.43 ; 0.90)$ & 0.01 \\
\hline \multicolumn{9}{|c|}{ Regular medication for other chronic diseases } \\
\hline No & 4540 & $1619(36)$ & $1870(41)$ & 1 (reference) & & $1051(23)$ & 1 (reference) & \\
\hline Yes & 716 & $418(58.5)$ & $182(25.5)$ & $0.48(0.37 ; 0.62)$ & $<0.001$ & $116(16)$ & $0.54(0.40 ; 0.72)$ & $<0.001$ \\
\hline \multicolumn{9}{|l|}{ Colds or Flu-like diseases frequency } \\
\hline Never & 1057 & $386(36.5)$ & $406(38.5)$ & 1 (reference) & & $265(25)$ & 1 (reference) & \\
\hline Occasionally, not every year & 1319 & $531(40)$ & $520(39.5)$ & $0.91(0.72 ; 1.16)$ & 0.5 & $268(20.5)$ & $0.73(0.55 ; 0.96)$ & 0.02 \\
\hline Once or twice a year & 1963 & $773(39.5)$ & $757(38.5)$ & $0.75(0.60 ; 0.93)$ & 0.01 & $433(22)$ & $0.68(0.54 ; 0.86)$ & 0.001 \\
\hline More than 3 times a year & 845 & $319(37.5)$ & $345(41)$ & $0.71(0.55 ; 0.92)$ & 0.01 & $181(21.5)$ & $0.61(0.46 ; 0.82)$ & 0.001 \\
\hline \multicolumn{9}{|c|}{ Influenza preventive homeopathic treatment } \\
\hline No & 3414 & $1570(46)$ & $1235(36)$ & 1 (reference) & & $609(18)$ & 1 (reference) & \\
\hline Yes & 1105 & $223(20)$ & $486(44)$ & $3.29(2.70 ; 4.00)$ & $<0.001$ & $396(36)$ & $4.85(3.84 ; 6.14)$ & $<0.001$ \\
\hline Don't know & 732 & $243(33)$ & $328(45)$ & $1.68(1.36 ; 2.09)$ & $<0.001$ & $161(22)$ & $1.73(1.34 ; 2.24)$ & $<0.001$ \\
\hline
\end{tabular}


Table 2b:Factors associated with the influenza vaccination opinion (multivaried analysis)

\begin{tabular}{|c|c|c|c|c|c|c|c|c|}
\hline Variables & $\mathbf{N}$ & $\begin{array}{c}\text { Positive } \\
\text { Opinion } \\
\text { n }(\%)\end{array}$ & $\begin{array}{l}\text { Neutral } \\
\text { Opinion } \\
\text { n }(\%)\end{array}$ & $\begin{array}{l}\text { Neutral Opinion vs } \\
\text { Positive Opinion } \\
\text { OR (IC 95\%) }\end{array}$ & $p$ value & $\begin{array}{l}\text { Negative } \\
\text { Opinion } \\
\text { n }(\%)\end{array}$ & $\begin{array}{c}\text { Negative } \\
\text { Opinion vs } \\
\text { Positive Opinion } \\
\text { OR (IC 95\%) } \\
\end{array}$ & p value \\
\hline \multicolumn{9}{|l|}{$\leq 1$ child between 5-18 years old in the household } \\
\hline No & 3696 & $1495(40.5)$ & $1384(37.5)$ & 1 (reference) & & $817(22)$ & 1 (reference) & \\
\hline Yes & 1560 & $542(34.5)$ & $668(43)$ & $0.76(0.62 ; 0.95)$ & 0.02 & $350(22.5)$ & $1.26(1.03 ; 1.53)$ & $\mathbf{0 . 0 3}$ \\
\hline \multicolumn{9}{|l|}{ Daily contacts with $>10$ individuals aged $\geq 65$} \\
\hline No & 4760 & $1800(38)$ & $1900(40)$ & 1 (reference) & & $1060(22)$ & 1 (reference) & \\
\hline Yes & 496 & $237(48)$ & $152(30.5)$ & $0.70(0.52 ; 0.94)$ & 0.01 & $107(21.5)$ & $0.89(0.64 ; 1.24)$ & 0.49 \\
\hline \multicolumn{9}{|l|}{ Daily contacts with patients } \\
\hline No & 4591 & $1718(37.5)$ & $1842(40)$ & 1 (reference) & & $1031(22.5)$ & 1 (reference) & \\
\hline Yes & 665 & $319(48)$ & $210(31.5)$ & $0.57(0.45 ; 0.72)$ & $<0.001$ & $136(20.5)$ & $0.54(0.40 ; 0.73)$ & $<0.001$ \\
\hline \multicolumn{9}{|l|}{ Level of Education } \\
\hline Master Degree or higher & 1536 & $659(43)$ & $602(39)$ & 1 (reference) & & $275(18)$ & 1 (reference) & \\
\hline Bachelor degree & 1206 & $418(35)$ & $495(41)$ & $1.46(1.23 ; 1.74)$ & $<0.001$ & $293(24)$ & $1.79(1.44 ; 2.22)$ & $<0.001$ \\
\hline High School Certificate or equivalent & 744 & $264(35.5)$ & $281(38)$ & $1.43(1.13 ; 1.81)$ & 0.002 & $199(26.5)$ & $2.08(1.58 ; 2.73)$ & $<0.001$ \\
\hline Lower than High School Certificate & 643 & $197(30.5)$ & $269(42)$ & $1.92(1.48 ; 2.47)$ & $<0.001$ & $177(27.5)$ & $2.64(1.97 ; 3.54)$ & $<0.001$ \\
\hline \multicolumn{9}{|l|}{ Main Activity } \\
\hline Full-time employment & 2247 & $810(36)$ & $956(42.5)$ & 1 (reference) & & $481(21.5)$ & 1 (reference) & \\
\hline Part-time employment & 509 & $167(33)$ & $202(39.5)$ & $1.03(0.80 ; 1.33)$ & 0.81 & $140(27.5)$ & $1.27(0.95 ; 1.71)$ & 0.10 \\
\hline Self-employed & 296 & $126(42.5)$ & $94(32)$ & $0.83(0.58 ; 1.18)$ & 0.28 & $76(25.5)$ & $1.36(0.94 ; 1.98)$ & 0.11 \\
\hline Student & 290 & $67(23)$ & $162(56)$ & $1.54(1.04 ; 2.28)$ & 0.04 & $61(21)$ & $1.21(0.74 ; 1.97)$ & 0.42 \\
\hline Home-maker (e.g. housewife) & 204 & $63(31)$ & $89(43.5)$ & $0.99(0.67 ; 1.47)$ & 0.95 & $52(25.5)$ & $0.89(0.55 ; 1.42)$ & 0.62 \\
\hline Unemployed & 182 & $50(27.5)$ & $77(42.5)$ & $1.19(0.74 ; 1.90)$ & 0.97 & $55(30)$ & $1.54(0.92 ; 2.56)$ & 0.10 \\
\hline Long-term sick-leave or Parental leave & 90 & $26(29)$ & $31(34.5)$ & $1.01(0.51 ; 2.01)$ & 0.97 & $33(36.5)$ & $2.10(1.06 ; 4.16)$ & 0.04 \\
\hline Retired & 1386 & $714(51.5)$ & $420(30.5)$ & $0.88(0.63 ; 1.23)$ & 0.43 & $252(18)$ & $0.68(0.46 ; 1.00)$ & 0.053 \\
\hline \multicolumn{9}{|l|}{ Population (number of inhabitants) } \\
\hline$[10000.100000)$ & 1796 & $667(37)$ & $744(41.5)$ & 1 (reference) & & $385(21.5)$ & 1 (reference) & \\
\hline$<200$ & 92 & $39(42.5)$ & $35(38)$ & $0.85(0.41 ; 1.76)$ & 0.07 & $18(19.5)$ & $0.68(0.32 ; 1.45)$ & 0.31 \\
\hline$[200-2,000)$ & 989 & $374(38)$ & $367(37)$ & $0.80(0.63 ; 1.02)$ & 0.06 & $248(25)$ & $1.00(0.76 ; 1.32)$ & 0.97 \\
\hline$[2,000-10,000)$ & 1338 & $524(39)$ & $514(38.5)$ & $0.87(0.71 ; 1.06)$ & 0.18 & $300(22.5)$ & $0.90(0.71 ; 1.13)$ & 0.36 \\
\hline$[100,000-1.000,000)$ & 728 & $304(42)$ & $270(37)$ & $0.68(0.54 ; 0.86)$ & 0.002 & $154(21)$ & $0.76(0.57 ; 1.02)$ & 0.07 \\
\hline$\geq 1.000,000$ & 313 & $129(41)$ & $122(39)$ & $0.95(0.67 ; 1.35)$ & 0.78 & $62(20)$ & $1.09(0.71 ; 1.68)$ & 0.68 \\
\hline
\end{tabular}


